\title{
Editorial
}

\section{Time and Mobility after the Anthropocene}

\author{
Pasi Heikkurinen ${ }^{1, *(\mathbb{D}}$, Toni Ruuska ${ }^{1}\left(\mathbb{0}\right.$, Anu Valtonen ${ }^{2}$ and Outi Rantala ${ }^{3}(\mathbb{C}$ \\ 1 Department of Economics and Management, University of Helsinki, 00500 Helsinki, Finland; \\ toni.ruuska@helsinki.fi \\ 2 Faculty of Social Sciences, University of Lapland, 96300 Rovaniemi, Finland; anu.valtonen@ulapland.fi \\ 3 Multidimensional Tourism Institute, University of Lapland, 96300 Rovaniemi, Finland; \\ outi.rantala@ulapland.fi \\ * Correspondence: pasi.heikkurinen@helsinki.fi
}

Received: 29 May 2020; Accepted: 4 June 2020; Published: 24 June 2020

check for updates

\begin{abstract}
The Special Issue on 'After the Anthropocene: Time and Mobility' is published. It discusses the geological time to follow the human-dominated epoch and ways to move there. In addition to this editorial, a total of five articles are published in the issue. The articles engage with a variety of social science disciplines-ranging from economics and sociology to philosophy and political science-and connect to the natural science insights on the Anthropocene. The issue calls for going beyond anthropocentrism in sustainability theory and practice in order to exit the Anthropocene with applications and insights in the contexts of politics (Ruuska et al., 2020), energy (Mohorčich, 2020), tourism (Rantala et al., 2020), food (Mazac and Tuomisto, 2020) and management (Küpers, 2020). We hope that you will find this Special Issue interesting and helpful in contributing to sustainable change.
\end{abstract}

Keywords: Anthropocene; time; mobility; nature; culture; sustainability

\section{Introduction}

The Anthropocene, characterized by global scale anthropogenic forcing since the latter part of the 18th century, is the name of the present geological epoch [1]. The empirical observations in Earth Sciences about the Anthropocene signify that a single species, Homo Sapiens, has grown its impacts on the rest of nature so vast that an exit from the previous epoch, Holocene, is seen as stratigraphically legitimate. The manifestations of the undesired global anthropogenic impacts on Earth include climate change and the loss of biodiversity.

Similarly, as the Holocene ended few centuries ago, it is imaginable that also one day the Anthropocene will be history. In fact, it seems quite obvious that sooner or later, the Earth will reach the end of the Anthropocene. The move to this time will be either with humans or without humans. The normative standpoint we wish to take here is that the Earth should move to this new post-Anthropocene time and humans should be active in this mission. Furthermore, it would be very desirable for humans themselves were they also to inhabit the time to follow the Anthropocene.

The scholarly debate to date has paid relatively little attention to this space-time. Instead, the discussion continues to revolve around questions such as: when did the human-dominated epoch began; what to call it; who or what is to blame for it; and how we might respond to it in the immediate future [2]. While these questions certainly deserve consideration, effort should also be aimed at questions of how the Anthropocene might come to an end (as a discourse and as an epoch); what post-Anthropocene might look like; and what this might signify for organizing social change, and/or caring for the nonhuman nature [3].

As the effects of changing climatic regimes impose greater effects on earthbound habitation and the known ways of being in the present geological epoch, there is a need to consider how humans and/or 
socio-nature might and should respond. That is, sustainability scholarship should begin imagining a time after the Anthropocene, when humans would no longer be the dominant species on the planet, and think of how to move there. We also consider the notion of the 'late Anthropocene' relevant for discussing the present when humanity-albeit in different place-specific ways-is forced to adapt in radical ways to the challenges that it faces.

\section{Peaceful Coexistence Colloquia}

The Special Issue 'After the Anthropocene: Time and Mobility' is titled after the theme of "The 3rd Peaceful Coexistence Colloquium" held in Helsinki 13-14 June 2019. This colloquium was organized by the University of Helsinki, Department of Economics and Management together with Sustainable Change Research Network (SUCH). "The 1st Peaceful Coexistence Colloquium" took place in Costa Rica at the University for Peace in 2015 with a theme 'Genders, Natures, and Technologies in the Anthropocene'. The second colloquium was hosted by University of Lapland in Pyhätunturi in 2017 with a theme "Reimagining Ethics and Politics of Space for the Anthropocene". The colloquiums are transdisciplinary meeting places for researchers, activists and artists who challenge the mainstream solutions for the challenges that face the Earth and its habitants. One of the aims of the Peaceful Coexistence Colloquium is also to call for alternative and more radical ways to address the current socio-economic crises.

All of these colloquiums have now produced an edited volume. The book "Sustainability and Peaceful Coexistence for the Anthropocene" connected to the first conference was edited by Pasi Heikkurinen and published in 2017 by Routledge [4]. To analyze the root problems and consequences of unsustainable development, as well as to outline rigorous solutions for the contemporary epoch, this volume brings together natural and social sciences under the rubric of the Anthropocene. The book identifies the central preconditions for social organization and governance to enable the peaceful coexistence of humans and the non-human world. The contributors investigate the burning questions of sustainability from a number of different perspectives including geosciences, economics, law, organizational studies, political theory, and philosophy. The book is a state-of-the-art review of the Anthropocene debate and provides crucial signposts for how human activities can, and should, be changed.

The book "Ethics and Politics of Space for the Anthropocene" linked to the second conference was edited by Anu Valtonen, Outi Rantala and Paolo Davide Farah and will be published in 2020 by Edward Elgar Publishing [5]. The book outlines new and more radical ways to address the current environmental crisis by envisaging a narrative of change that renders visible the range of transformations taking place throughout the globe. This enables the authors to capture the complex nature of ongoing transformations and to alter unjust practices and power structures in a sustainable and context-specific manner. Importantly, the new narrative highlights the localized and situated nature of the Anthropocene, allowing the differences of regions and contexts-and subsequent ethical and political questions--to be taken seriously. It also highlights the potentiality residing in non-Western ways of relating to and living on the earth, taking more-than-humans into account.

This Special Issue "After the Anthropocene: Time and Mobility" is an output from the third conference and published in 2020 by the journal "Sustainability". At the dawn of spring 2019, we were contacted by the Editorial Board of the journal concerning a Special Issue and we suggested the same theme and title as the third Peaceful Coexistence. In the opening words of the colloquium the Special Issue was introduced to the participants, which were also invited to write an article to it. The colloquium itself had 35 participants from 10 different countries. The presentations and talks under the theme were diverse ranging from deep ecology, and indigenous food sovereignty to degrowth, and non-human hauntology. This final edited volume will end the Anthropocene-thematic trilogy in the Peaceful Coexistence collective.

"The 4th Peaceful Coexistence Colloquium" is going to be held in 2021 and organized by Sustainable Change Research Network (SUCH). We invite all interested persons to contact us. 


\section{Articles in the Issue}

This Special Issue comprises five articles, which all explore and discuss ways out of the Anthropocene, as well as envisage possibilities for diverse life after the Anthropocene. The focus of the issue is on questions of time and mobility, insofar as these concepts enrich our understandings of what comes after the Anthropocene and how could an exit from the Anthropocene materialize. The articles explore time and mobility after the Anthropocene in different ways, from a rich diversity theoretical and empirical point of views.

In their article 'Domination, Power, Supremacy: Confronting Anthropolitics with Ecological Realism,' Ruuska et al. [6] studied politics as domination. They claimed that domination, especially in the Anthropocene, has two vital components, which are power and supremacy. Domination does not occur without the power over others. In addition, domination requires reasoning, justification, and legitimation that are often connected to superiority arguments (based on religion, society, civilization, etc.) from the oppressor's end. The authors argued that past and present political ideologies and agendas, such as colonial rule, imperialism, neoliberal capitalism, and also the popular Green New Deal are examples of 'anthropolitics', entailing an anthropocentric approach to politics. In contrast to historical and prevailing anthropolitical programs, the article discusses post-Anthropocene politics under a theoretical frame called ecological realism, which is characterized by equality among beings, and localization and decentralization, as well as steep reduction of matter-energy throughput in the human realm.

In his article 'Energy Intensity and Human Mobility after the Anthropocene,' Mohorčich [7] claimed that after the Anthropocene, human settlements will likely have less available energy to move people and things. His article considered the feasibility of five modes of transportation under two energy-constrained scenarios. Mohorčich analyzed the effects that transformation mode choice is likely to have on the size of post-Anthropocene human settlements, and also what is the role of speed and energy in them. He argued that cars (including battery-electric vehicles) are not feasible under a highly energy-constrained situation, in contrast to buses, metros and walking which are feasible, but limit human settlement size. Cycling is likely the only mode of transport that would enable suburbs in an energy-constrained post-Anthropocene scenario, the article concludes.

In their article 'Envisioning Tourism and Proximity after the Anthropocene', Rantala et al. [8] called for new imaginings, conceptualizations and practices of tourism for the current Earthly crisis. Thus, they conceptualized proximity tourism with feminist new materialist literature, which accords agency to the ongoing common worlding of all matter-including but not limited to humans-rather than to separate individual agents. More specifically, they explore the idea of proximity by drawing closer to the geo—-to the Earth —-through geological walks in the Pyhä National Park in Finnish Lapland. These walks are analyzed with the notions of rhythmicity, vitality and care-ideas constructed from the theoretical heritage guiding the study. By doing this, Rantala, Salmela, Valtonen, and Höckert explore the potential of proximity tourism in ways that intertwine non-living and living matter, science stories, history, local communities, and tourism. The outcome of this analysis is that they compose one possible narrative of tourism after the Anthropocene.

In their article 'The Post-Anthropocene Diet: Navigating Future Diets for Sustainable Food Systems,' Mazac and Tuomisto [9] examined how future diets could reduce the environmental impacts of food systems, and thus, enable movement into the post-Anthropocene. The authors claimed that non-anthropocentric diets could address global food systems challenges in the Anthropocene. In order to change diets, changes in ontology is proposed. In their article, Mazac and Tuomisto employed indigenous worldviews and object-oriented ecosophy to investigate the possibilities of non-anthropocentric worldviews with a focus on temporality. While indigenous ontologies are introduced as pre-Anthropocene examples that depict humans and non-humans in relational diets, a post-Anthropocene illustration stresses non-dualist object-oriented ecosophy. As a central implication, the article offered ontologically based ideas to developing dietary guidelines for the time after the Anthropocene. 
In his article "From the Anthropocene to an "Ecocene"-Eco-Phenomenological Perspectives on Embodied, Anthrodecentric Transformations towards Enlivening Practices of Organising Sustainably', Küpers [10] discussed the Anthropocene from an eco-phenomenological point of view. The author drew, in particular, on the work of Maurice Merleau-Ponty on 'body'. The article challenges body-mind dualism and the hyper-separation between nature and culture inherent in the Anthropocene. It calls for moving from the Anthropocene to Ecocene by making, what Küpers calls, an anthro-decentric transformation. The article ends by presenting implications for sustainable organizing where the role of the body and embodiment have a central stage. Moreover, the author notes that moving 'towards a more integral ecocene necessitates an ethico-political restructuring and transformation of contemporary organizations [ ... ]', which ' $[\ldots]$ involves analysing and questioning anthropocentric and interest-centric political practices and how they are used to accomplish and uphold power or control' (p. 12).

\section{Conclusions}

Based on the articles of this issue, it is evident to us that now is the time to move out from the Anthropocene. Just as the Anthropocene marked a global matter-energetic shift, this end of the human epoch also marks significant changes in the deep geological time of the Earth's history. Different temporal perspectives and rhythms will play a role in how the time after the Anthropocene will unfold. There is a need to begin to conceive time not only in anthropocentric terms, but more deeply and holistically, for instance, in terms of minerals, plants, and animals [2]. Thus, instead of merely seeking to save the world for future human generations, consideration and care of non-human objects, like rocks—constituents of the Earth—opens up a different time horizon, as the emerging geo-social literature cogently demonstrates [11,12].

A possibility is that the on-going mass movement of people and other earthbound beings will both be an outcome and reason for the new epoch. Furthermore, the travel of earthbound beings beyond the boundaries of Earth - the exploitation of space-is an issue calling for serious critical reflection. Finally, the mobility of deep geological formations of the Earth merits consideration as well; the movement of lithospheric plates has historically changed the course of life on the planet in a remarkable way. The trouble of moving, living, and dying together in the late Anthropocene necessarily brings about new practical and theoretical questions of power, as the recent formulations of 'geopower', for instance, highlight [13].

Finally, this scenario demands us to begin to develop post-anthropocentric ways of theorizing and doing research. There is a need to find a better balance in how all habitants of the earth are included in theory making, and involved in theoretical narration. A recent study of mosquitoes in the context of tourism provides a case in point [14]. Drawing from feminist new material literature, the authors suggest a post-anthropocentric approach that casts mosquitoes as fellow travelers, with which we are to live with-no matter whether we like it or not. The inevitable common worlding with multiple others, including tiny ones, needs to be better acknowledged in future theorizations.

The entanglement of humans with various creatures is strikingly visible now that the COVID-19 entangles with our bodies, bringing about major social, political, and economic consequences. It has forced us to consider many commonplace habits anew, including travelling. Ecologically, the pandemic might trigger a shift, even though the history suggests that 'business-as-usual' is plausible after the crisis [15]. Nevertheless, the pandemic efficiently highlights that the concept of the human mastery and control over other creatures is just an illusion.

Author Contributions: The authors' contribution to the special issue and this editorial corresponds with the order of the authors listed in this article. All authors contributed substantially to all tasks. All authors have read and agreed to the published version of the manuscript.

Funding: This research received no external funding.

Conflicts of Interest: The authors declare no conflict of interest. 


\section{References}

1. Crutzen, P.J.; Stoermer, E.F. The Anthropocene. Glob. Chang. Newsl. 2000, 41, 17-18.

2. Heikkurinen, P.; Rinkinen, J.; Järvensivu, T.; Wilén, K.; Ruuska, T. Organising in the Anthropocene: An ontological outline for ecocentric theorising. J. Clean. Prod. 2016, 113, 705-714. [CrossRef]

3. Heikkurinen, P.; Ruuska, T.; Wilén, K.; Ulvila, M. The Anthropocene exit: Reconciling discursive tensions on the new geological epoch. Ecol. Econ. 2019, 164, 106369. [CrossRef]

4. Heikkurinen, P. (Ed.) Sustainability and Peaceful Coexistence for the Anthropocene; Routledge: Abingdon, UK, 2017.

5. Valtonen, A.; Rantala, O.; Farah, P. (Eds.) Ethics and Politics of Space for the Anthropocene; Edwar Elgar Publishing: Cheltenham, UK, 2020. (in press)

6. Ruuska, T.; Heikkurinen, P.; Wilén, K. Domination, Power, Supremacy: Confronting Anthropolitics with Ecological Realism. Sustainability 2020, 12, 2617. [CrossRef]

7. Mohorčich, J. Energy Intensity and Human Mobility after the Anthropocene. Sustainability 2020, $12,2376$. [CrossRef]

8. Rantala, O.; Salmela, T.; Valtonen, A.; Höckert, E. Envisioning Tourism and Proximity after the Anthropocene. Sustainability 2020, 12, 3948. [CrossRef]

9. Mazac, R.; Tuomisto, H.L. The Post-Anthropocene Diet: Navigating Future Diets for Sustainable Food Systems. Sustainability 2020, 12, 2355. [CrossRef]

10. Küpers, W. From the Anthropocene to an 'Ecocene'-Eco-Phenomenological Perspectives on Embodied, Anthro-Dece Ntric Transformations towards Enlivening Practices of Organising Sustainably. Sustainability 2020, 12, 3633. [CrossRef]

11. Clark, N.; Yusoff, K. Geosocial formations and the Anthropocene. Theory Cult. Soc. 2017, 34, 3-23. [CrossRef]

12. Yusoff, K. Anthropogenesis: Origins and endings in the Anthropocene. Theory Cult. Soc. 2016, 33, 3-28. [CrossRef]

13. Grosz, E. Geopower. Environ. Plan. D Soc. Space 2012, 30, 973-975.

14. Valtonen, A.; Salmela, T.; Rantala, O. Living With Mosquitoes. Ann. Tour. Res. 2020. [CrossRef]

15. Ioannides, D.; Szilvia, G. The COVID-19 crisis as an opportunity for escaping the unsustainable global tourism path. Tour. Geogr. 2020. [CrossRef] 